\title{
CARDIOPULMONARY EFFECTS OF 7.2\% SALINE SOLUTION COMPARED WITH GELATIN INFUSION IN THE EARLY POSTOPERATIVE PERIOD AFTER CORONARY ARTERY BYPASS GRAFTING
}

Rashid Mazhar, FCPS, FRCS

Adrian Samenesco, MBBS

David Royston, FRCA

Alun Rees, FRCS

\begin{abstract}
Objective: We report a clinical study on the use of $7.2 \%, 2400 \mathrm{mOsm} / \mathrm{L}$, hypertonic saline solution compared with gelatin in early postoperative period after coronary artery bypass surgery. Methods: Two groups $(n=10$ each) received $5 \mathrm{ml} / \mathrm{kg}$ of either saline solution or gelatin over 1 hour. Cardiac index, central venous pressure, pulmonary capillary wedge pressure, systemic and pulmonary vascular resistance indices, arterial oxygen tension, plasma osmolarity, electrolytes, and urinary output were recorded before starting the infusion and subsequently at 10, 30, 60, 90, 120, 240 and 600 minutes. Plasma creatinine, urea, electrolytes, urinary volume, and sodium excretion were measured at 12 and 24 hours. Results: There were no significant demographic or operative differences between the groups. Patients receiving saline solution had a larger diuresis at $12(p=0.0008)$ and 24 hours $(p=0.002)$, with less positive balance at 12 hours $(p=$ 0.0008). The group receiving saline solution had better cardiorespiratory recovery with shorter extubation time $(p=0.033)$, and earlier increase in cardiac index with a positive correlation between plasma sodium content and cardiac index. Maximum increase in cardiac index $(+31 \%)$ occurred at 60 minutes $(p=0.025)$ associated with $8 \%$ increase in plasma sodium content $(r=0.51, p=0.01)$, without a concomitant rise in pulmonary capillary wedge pressure. The group receiving gelatin had a linear increase in cardiac index with increasing pulmonary capillary wedge pressure, reaching $+16 \%$ from baseline by 90 minutes. Compared with the gelatintreated group, patients receiving saline solution had unchanged systemic vascular resistance index but a significantly lower pulmonary vascular resistance index with a negative correlation to plasma sodium content. There was no difference in levels of urea and creatinine. No side-effect attributable to the use of saline solution was observed. (J Thorac Cardiovasc Surg 1998;115:178-89)
\end{abstract}

C ardiopulmonary bypass (CPB) is known to produce fluid retention ${ }^{1}$ and disturbed microcirculation $^{2}$ along with depressed cardiorespiratory state for a variable period after the operation. The exact cause or the changes leading to this state are unclear.

From the Department of Cardio-Thoracic Surgery, Harefield Hospital, Harefield, Middlesex, London, United Kingdom.

Received for publication Jan. 27, 1997; revisions requested March 11, 1997; revisions received July 31, 1997; accepted for publication July 31, 1997.

Address for reprints, R. Mazhar, FRCS, Department of CardioThoracic Surgery, Harefield Hospital, Harefield, Middlesex, UB9 6JH, London, United Kingdom.

Copyright (C) 1998 by Mosby, Inc.

$0022-5223 / 98 \$ 5.00+0 \quad \mathbf{1 2 / 1 / 8 5 2 7 3}$
We have conducted this study with the hypothesis that during the protracted hypotensive state of CPB, significant endothelial and visceral edema ensues, subsequent to the breakdown of energy-dependent volume-regulatory mechanisms, contributing to multiorgan dysfunction. Increasing plasma osmolarity with an electrolyte solution (hypertonic saline solution, HTS) that would not avidly cross into the intracellular compartment can be expected to osmotically reverse this presumed intracellular fluid retention and hence generally improve endothelial, myocardial, and other visceral function.

Experimental use of hyperosmolar saline solutions is not new. In 1919, Penfield ${ }^{3}$ described the use of $2 \%$ sodium bicarbonate in hypovolemic dogs. In 1973, Moylan, Reckler, and Mason ${ }^{4}$ reported the 
usefulness of $1.8 \%$ saline solution in the treatment of patients with shock caused by burns. In 1980, De Flippe and coworkers, ${ }^{5}$ using $7.5 \%$ HTS, successfully treated nine of 12 patients with severe hypovolemic shock of varied causes. Since these reports, interest has been renewed in "small volume resuscitation" using hyperosmolar salt solutions in the treatment of trauma, ${ }^{6}$ during aortic operations, ${ }^{7}$ during cardiogenic shock, ${ }^{8}$ and during cardiac anesthesia. ${ }^{9}$ Most of these studies used a mixture of HTS with a synthetic colloid (dextran or hydroxyethyl starch). Observations made on infusion of a mixture of two synergistically active ingredients may have blurred the effects of HTS alone.

Cross and associates ${ }^{10}$ have gainfully used weak HTS $(1.8 \%)$, comparing it with $0.9 \%$ saline solution, after coronary artery bypass grafting (CABG). However, the condition of their subjects was hemodynamically stabilized by means of synthetic colloids and blood products before the HTS solution was administered. The role of HTS alone in the early post-CABG period has not been studied. For the present study we have used $7.2 \%$ HTS, because when the concentration is above $7.5 \%$ not only does hemolysis occur but the hemodynamic effects plateau as well. ${ }^{11}$

GEL (gelatin; Haemaccel, Hoechst-Roussel Pharm, Inc., Somerville, N.J.) is the standard primary volume expander at our institution; hence it was used as the control.

\section{Patients and methods}

Design: Prospective, randomized, double-blind trial. The study was approved by the hospital ethical committee and informed consent was obtained form all patients.

Subjects. The study comprised 20 adult patients undergoing elective $\mathrm{CABG}$. Exclusion criteria were age older than 75 years, preoperative ejection fraction less than $35 \%$, plasma creatinine content greater than $135 \mu \mathrm{mol} / \mathrm{L}$, preoperative angiotensin-converting enzyme inhibitors, need for inotropic support, and postoperative bleeding more than $200 \mathrm{ml} / \mathrm{hr}$ or necessitating resternotomy for hemostasis. During the period of the study, all randomly contacted patients except one consented to participate in the study. There were no postoperative exclusions.

Methods

Anesthesia and surgery. All operations (CABG) were performed by a single surgical and anesthetic team. A thermodilution catheter was inserted before the operation in all patients. CPB was instituted with a nonpulsatile pump (Medtronic Bio-Medicus, Eden Prairie, Minn.) and an Avecor affinity membrane oxygenator (Avecor Cardiovascular, Inc., Plymouth, Minn.). The myocardium was protected by the use of systemic hypothermia to $28^{\circ} \mathrm{C}$, topical ice slush, and intermittent, antegrade, crystalloid cardioplegia with St. Thomas' Hospital solution $(15 \mathrm{ml} / \mathrm{kg})$ repeated every 30 minutes at $7 \mathrm{ml} / \mathrm{kg}$. Pump prime consisted of Hartmann's solution $500 \mathrm{ml}$, GEL $500 \mathrm{ml}$, $20 \%$ mannitol $150 \mathrm{ml}$, and heparin 5000 units given intravenously. Additional Hartmann's solution was used to maintain the reservoir volume at a minimum of $500 \mathrm{ml}$. Packed red cells were transfused if the hemoglobin value was less than $8 \mathrm{gm} / \mathrm{dl}$.

Postoperative fluids. In the intensive treatment unit $4 \%$ dextrose $/ 0.18 \%$ saline solution with $20 \mathrm{mmol} \mathrm{K}^{+}$, at a rate of $1 \mathrm{ml} / \mathrm{kg}$, was given as maintenance fluid. Patients were assigned to receive $5 \mathrm{ml} / \mathrm{kg}$ of either $7.2 \%$ HTS (2400 $\mathrm{mOsm} / \mathrm{L}, \mathrm{Na}^{+}$and $\mathrm{Cl}^{-} 1200 \mathrm{mEq} / \mathrm{L}$ each) or GEL (Polygeline [degraded and modified gelatin, average molecular weight 30,000$] 35 \mathrm{gm}, \mathrm{Na}^{+}$and $\mathrm{Cl}^{-}$content $145 \mathrm{mEq} / \mathrm{L}$ each, $\mathrm{Ca}^{++} 6.25 \mathrm{mmol} / \mathrm{L}$, osmolarity $301 \mathrm{mOsm} / \mathrm{L}$ ) over 1 hour. The fluid was prepared by the pharmacy department, and the investigators were blinded to the solution in use. Additional fluid infusion was administered by the intensive training unit nurse caring for the patient if the central venous pressure or pulmonary capillary wedge pressure fell to $5 \mathrm{~mm} \mathrm{Hg}$ or if the blood pressure was below $80 / 50 \mathrm{~mm} \mathrm{Hg}$. The identity code of the solution was broken at the completion of the study. GEL or packed red cells, or both (if the hemoglobin value was less than 9 $\mathrm{gm} / \mathrm{L}$ ), were administered to maintain these values.

Ventilation/extubation. Postoperative ventilation was adjusted to maintain arterial oxygen tension greater than $12 \mathrm{kPa}$, carbon dioxide tension 4.5 to $5 \mathrm{kPa}$, and $\mathrm{pH}$ greater than 7.32. Patients were extubated according to the following criteria: awake, respiratory rate less than 30 breaths/min, inspired oxygen fraction less than 0.5 , arterial oxygen tension more than $10 \mathrm{kPa}$, tidal volume greater than $5 \mathrm{ml} / \mathrm{kg}$, arterial carbon dioxide tension less than 5.5 $\mathrm{kPa}$, minimal bleeding $(<50 \mathrm{ml} / \mathrm{hr})$, and axillary temperature greater than $36.5^{\circ} \mathrm{C}$.

Fluid balance. Intraoperative fluid balance was calculated as follows: (fluids infused [crystalloid + colloid] + pump prime + cardioplegia + blood $)-$ (diuresis + volume left in the pump + volume in the suction's reservoir). Insensible losses were not accounted for in either group.

Measurements and monitoring. Measurements were made before the start of HTS or GEL infusion (baseline) and at 10, 30, 60 (end of infusion), 90, 120, 240, 400, and 600 minutes afterward. At each point, the following three groups of parameters were noted:

1. Hemodynamic parameters: heart rate, blood pressure, central venous pressure, pulmonary capillary wedge pressure, systemic and pulmonary vascular resistance indices (SVRI and PVRI), and cardiac index (CI)

2. Respiratory parameters: arterial oxygen and carbon dioxide tensions, bicarbonate and arterial base excess, inspired oxygen fraction, and minute respiratory volume

3. Metabolic/renal parameters: plasma sodium, potassium, urea, creatinine, glucose, and osmolarity

Urinary output and sodium excretion at 12 and 24 hours were recorded.

Statistics. The data were analyzed with the use of SPSS for Windows (version 6) (SPSS, Inc., Chicago, Ill.) and Microsoft Excel software package (Microsoft Corporation, Redmond, Wash.). For parameters with multiple 
Table I. Demographics

\begin{tabular}{|c|c|c|c|c|c|c|c|}
\hline & \multicolumn{3}{|c|}{ HTS } & \multicolumn{3}{|c|}{$G E L$} & \multirow[b]{2}{*}{$p$ Value } \\
\hline & Mean & SEM & $S D$ & Mean & SEM & $S D$ & \\
\hline Age (yr) & 57.1 & 2.5 & 7.8 & 60.1 & 2.4 & 7.8 & 0.2 \\
\hline Weight (kg) & 81.6 & 3.2 & 10.2 & 73.5 & 3.2 & 10.2 & 0.09 \\
\hline $\operatorname{BSA}\left(\mathrm{m}^{2}\right)$ & 1.9 & 0.05 & 0.2 & 1.9 & 0.05 & 0.2 & 0.1 \\
\hline $\mathrm{EF}$ & 54.3 & 5.7 & 18.05 & 63.7 & 3.7 & 11.8 & 0.2 \\
\hline CPB (min) & 102 & 9.2 & 29.1 & 112.5 & 7.1 & 22.5 & 0.4 \\
\hline $\mathrm{X}$-clamp (min) & 66.2 & 6.3 & 19.9 & 65.8 & 4.7 & 14.8 & 0.7 \\
\hline
\end{tabular}

$S E M$, Standard error of mean; $S D$, standard deviation; $B S A$, body surface area; $E F$, ejection fraction; $C P B$, cardiopulmonary bypass time (minutes); $X$-clamp, crossclamp time.

Table II. Fluid balance and extubation time

\begin{tabular}{|c|c|c|c|c|c|c|c|}
\hline & \multicolumn{3}{|c|}{ HTS } & \multicolumn{3}{|c|}{$G E L$} & \multirow[b]{2}{*}{$p$ Value } \\
\hline & Mean & Median & $S D$ & Mean & Median & $S D$ & \\
\hline Intraop. balance & 52.6 & 53.0 & 24.5 & 54.2 & 54.2 & 23.7 & 0.8 \\
\hline Blood & 4.5 & 4.0 & 3.3 & 5.9 & 4.25 & 4.3 & 0.5 \\
\hline Gelatin & 13.0 & 13.6 & 7.4 & 17.3 & 15.2 & 8.8 & 0.3 \\
\hline Crystalloid (dextrose saline) & 10.4 & 10.8 & 2.3 & 12.7 & 12.0 & 4.6 & 0.2 \\
\hline $12 \mathrm{hr}$ total input & 32.9 & 35.1 & 10.5 & 40.8 & 38.3 & 13.4 & 0.2 \\
\hline $12 \mathrm{hr}$ chest drainage & 4.7 & 3.7 & 2.6 & 5.35 & 5.0 & 2.4 & 0.1 \\
\hline $12 \mathrm{hr}$ urinary output & 51.25 & 43.8 & 18.3 & 26.5 & 26.0 & 9.1 & 0.0008 \\
\hline $24 \mathrm{hr}$ urinary output & 66.4 & 60.3 & 22.0 & 39.3 & 38.8 & 10.1 & 0.002 \\
\hline Total output at $12 \mathrm{hr}$ & 55.9 & 46.8 & 20.28 & 31.9 & 31.7 & 10.6 & 0.001 \\
\hline $12 \mathrm{hr}$ postop. balance & -23 & -26.4 & 17.6 & 8.9 & 8.0 & 10.1 & 0.0008 \\
\hline NET balance (intraop. $+12 \mathrm{hr}$ postop.) & 29.6 & 32.1 & 18.1 & 63.1 & 71.7 & 23.2 & 0.007 \\
\hline Extubation time (min) & 410.9 & 405 & 67.8 & 625 & 630 & 242 & 0.02 \\
\hline
\end{tabular}

Values are given in milliliters per kilogram of body weight. Boldface type indicates significant $p$ values.

Table III. Plasma and urinary biochemistry

\begin{tabular}{|c|c|c|c|c|c|c|c|}
\hline & \multicolumn{3}{|c|}{ HTS } & \multicolumn{3}{|c|}{$G E L$} & \multirow[b]{2}{*}{$p$ Value } \\
\hline & Mean & Median & $S D$ & Mean & Median & $S D$ & \\
\hline P. $\mathrm{Na}^{+} 12 \mathrm{hr}$ & 148.6 & 147.0 & 4.6 & 141.7 & 142.0 & 2.3 & 0.0003 \\
\hline P. $\mathrm{Na}^{+} 24 \mathrm{hr}$ & 138.1 & 138.0 & 3.9 & 136.9 & 136.0 & 3.8 & 0.19 \\
\hline P. Urea $12 \mathrm{hr}$ & 6.1 & 6.0 & 1.2 & 6.3 & 5.5 & 1.8 & 0.72 \\
\hline P. Urea $24 \mathrm{hr}$ & 8.1 & 6.7 & 3.4 & 5.7 & 6.0 & 1.3 & 0.13 \\
\hline P. Creat. 12 hr & 104.6 & 106.0 & 10.7 & 96.9 & 94.0 & 20.5 & 0.22 \\
\hline P. Creat. $24 \mathrm{hr}$ & 106.4 & 102.5 & 16.3 & 97.4 & 100.5 & 18.1 & 0.32 \\
\hline Ur. $\mathrm{Na}^{+} 12 \mathrm{hr}$ & 533.3 & 544.5 & 178.8 & 181.8 & 177.5 & 50.6 & 0.00009 \\
\hline Ur. $\mathrm{Na}^{+} 24 \mathrm{hr}$ & 188.9 & 150 & 108.8 & 74.3 & 71.0 & 22.2 & 0.0009 \\
\hline
\end{tabular}

P. $\mathrm{Na}^{+} 12 \mathrm{hr}$, Plasma sodium at 12 hours (Meq/L); $P . \mathrm{Na}^{+} 24 \mathrm{hr}$, plasma sodium at 24 hours (Meq/L); P. Urea $12 \mathrm{hr}$, plasma urea at $12 \mathrm{hours}(\mathrm{mmol} / \mathrm{L}) ; P$. Urea $24 \mathrm{hr}$, plasma urea at 24 hours $(\mathrm{mmol} / \mathrm{L}) ; P$. Creat. $12 \mathrm{hr}$, plasma creatinine at 12 hours, $(\mu \mathrm{mol} / \mathrm{L}) ; P$. Creat $24 \mathrm{hr}$, plasma creatinine at $24 \mathrm{hours}(\mu \mathrm{mol} / \mathrm{L})$; $\mathrm{Ur} . \mathrm{Na}^{+} 12 \mathrm{hr}$, urinary sodium excretion at 12 hours (mmol/L); $U r . N a^{+} 24 \mathrm{hr}$, urinary sodium excretion at 24 hours $(\mathrm{mmol} / \mathrm{L})$.

measurements, two-way analysis of variance was used to simultaneously evaluate the effects of time and group. The Spearman test was used for correlation of the parameters at different time points. Nonserial observations were compared by means of the Wilcoxon-Mann-Whitney test. Significance was taken at $p<0.05$. Of the measured parameters, SVRI and CI were found to be significantly different in the two groups at their baseline values. Hence these were compared after the raw data had been transformed into values depicting change from their baseline levels. For example, change in $\mathrm{CI}$ at a time point $(\mathrm{t})=\mathrm{CI}$ (0) [minus] CI (t), where CI (0) is the baseline value.

\section{Results}

The two groups did not differ with regard to the anesthetic, CPB, and operative techniques. Although the GEL group included three women whereas the HTS group was all male, no significant 


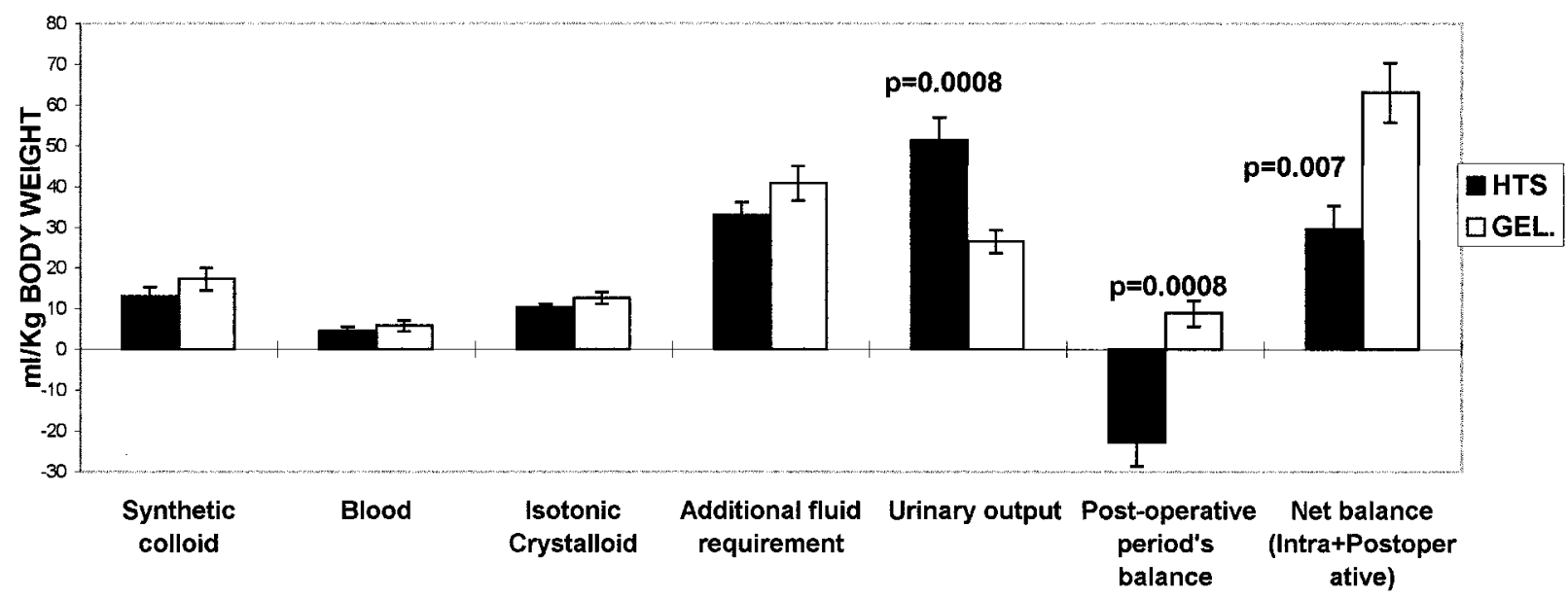

Fig. 1. Fluid requirement of the two groups, with and without inclusion of the intraoperative fluid balance. Values depicted are mean \pm standard error of mean. Additional fluid requirement is the sum total of the volume of the synthetic colloid, blood, and isotonic crystalloid given besides the test/control fluid in the first 12 postoperative hours. Postoperative balance denotes the balance for this postoperative period alone, and Net balance incorporates the intraoperative fluid balance as well.

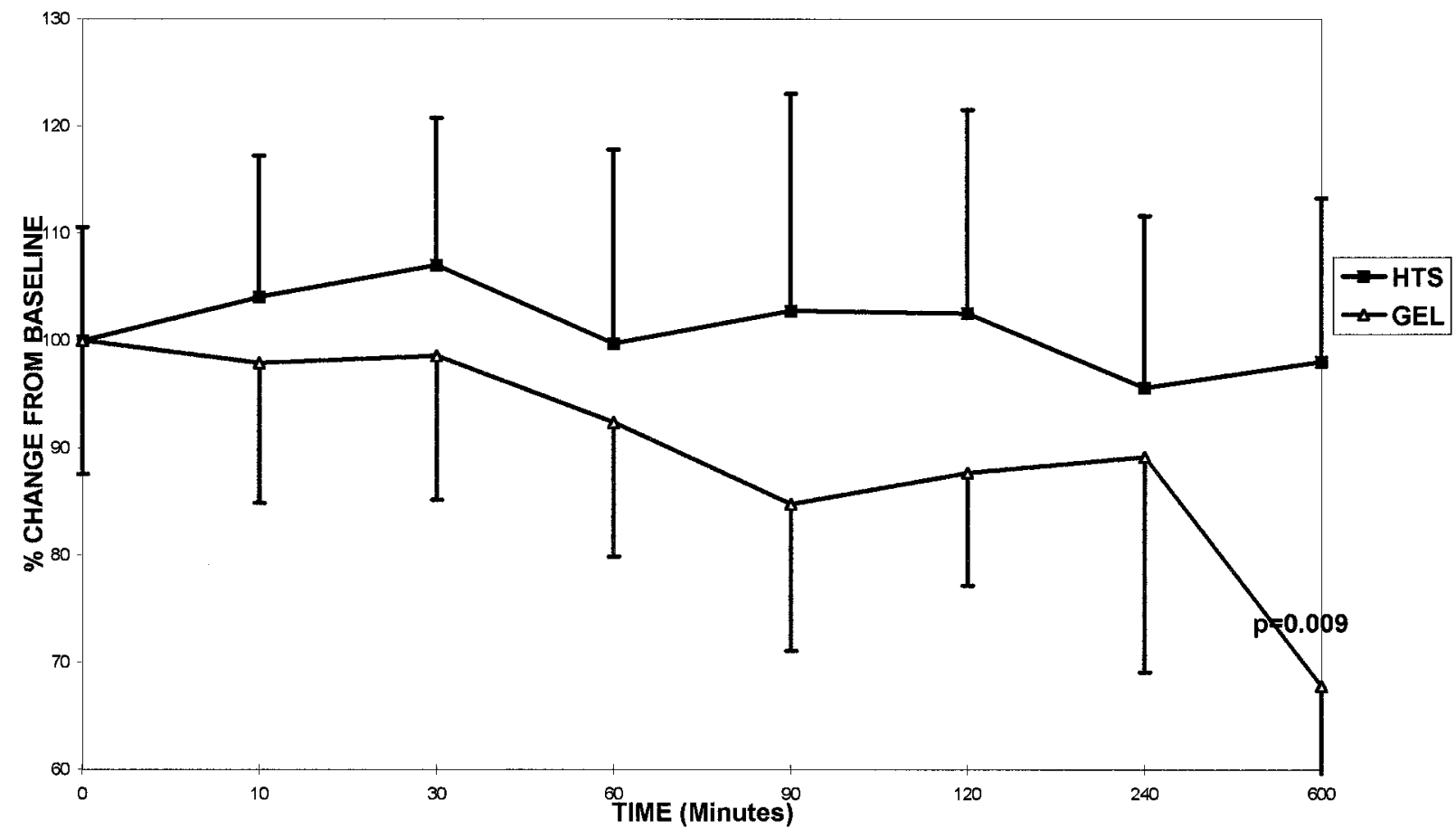

Fig. 2. Comparison of the percentage change (from the preoperative value) in the SVRI of the two groups. Values depicted are mean \pm standard error of the mean. 


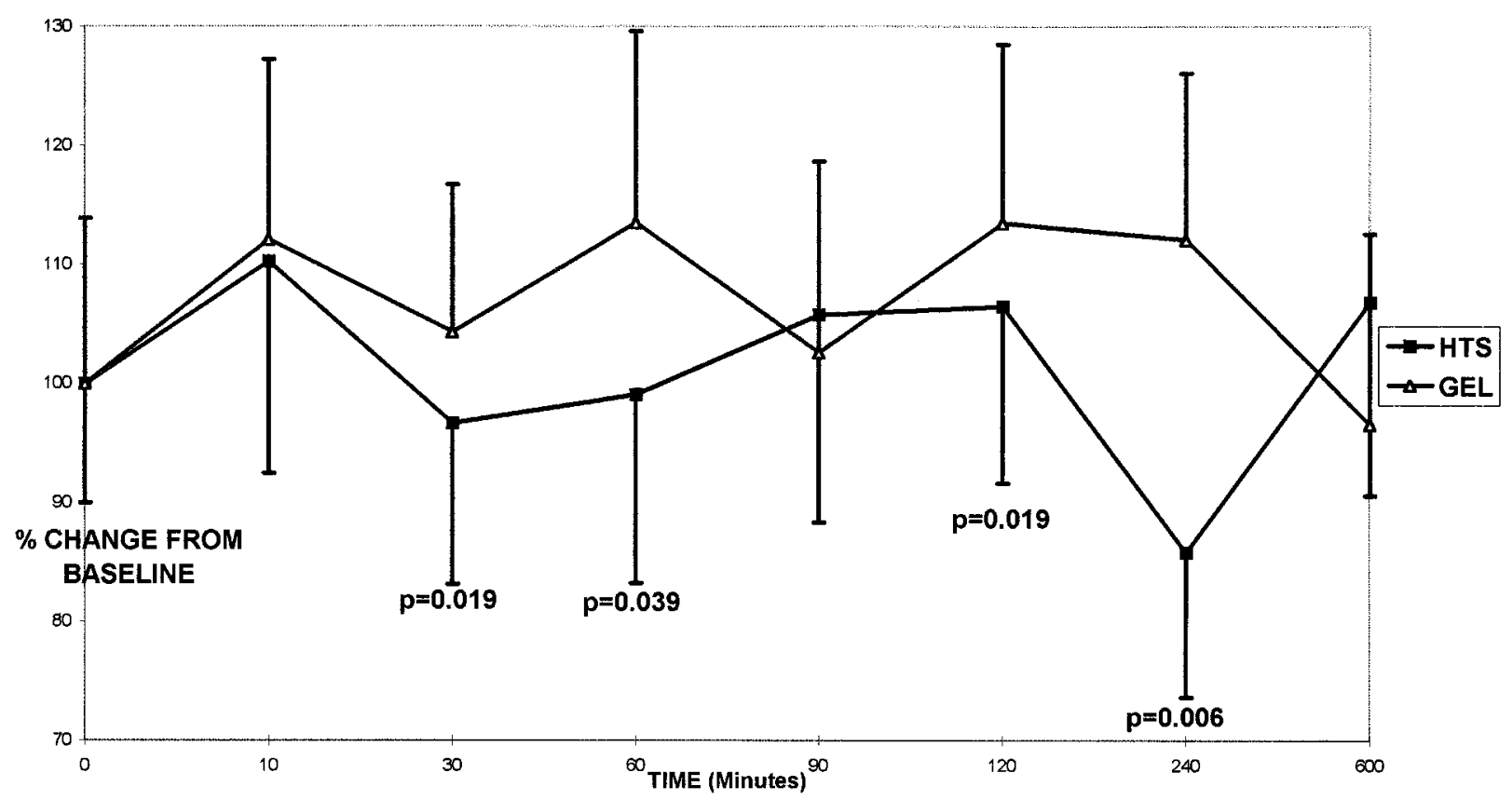

Fig. 3. Comparison of the percentage change (from the preoperative value) in the PVRI of the two groups. Values depicted are mean \pm standard error of the mean.

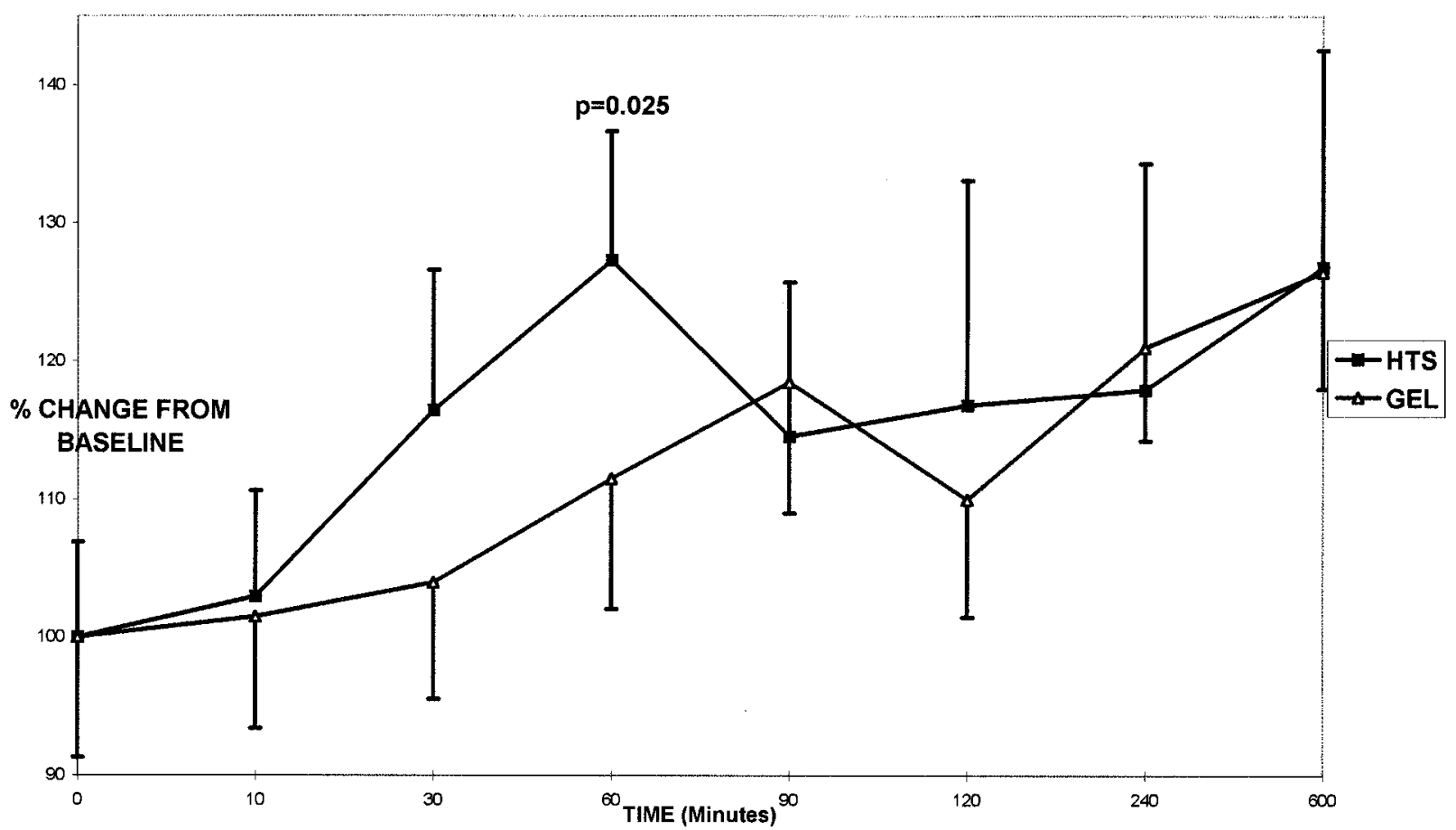

Fig. 4. Percentage changes from the preoperative value in the CI of the two groups. Note an early and increasing rise in the CI of the HTS group for the time period of infusion of the HTS solution. Values depicted are mean \pm standard error of the mean. 


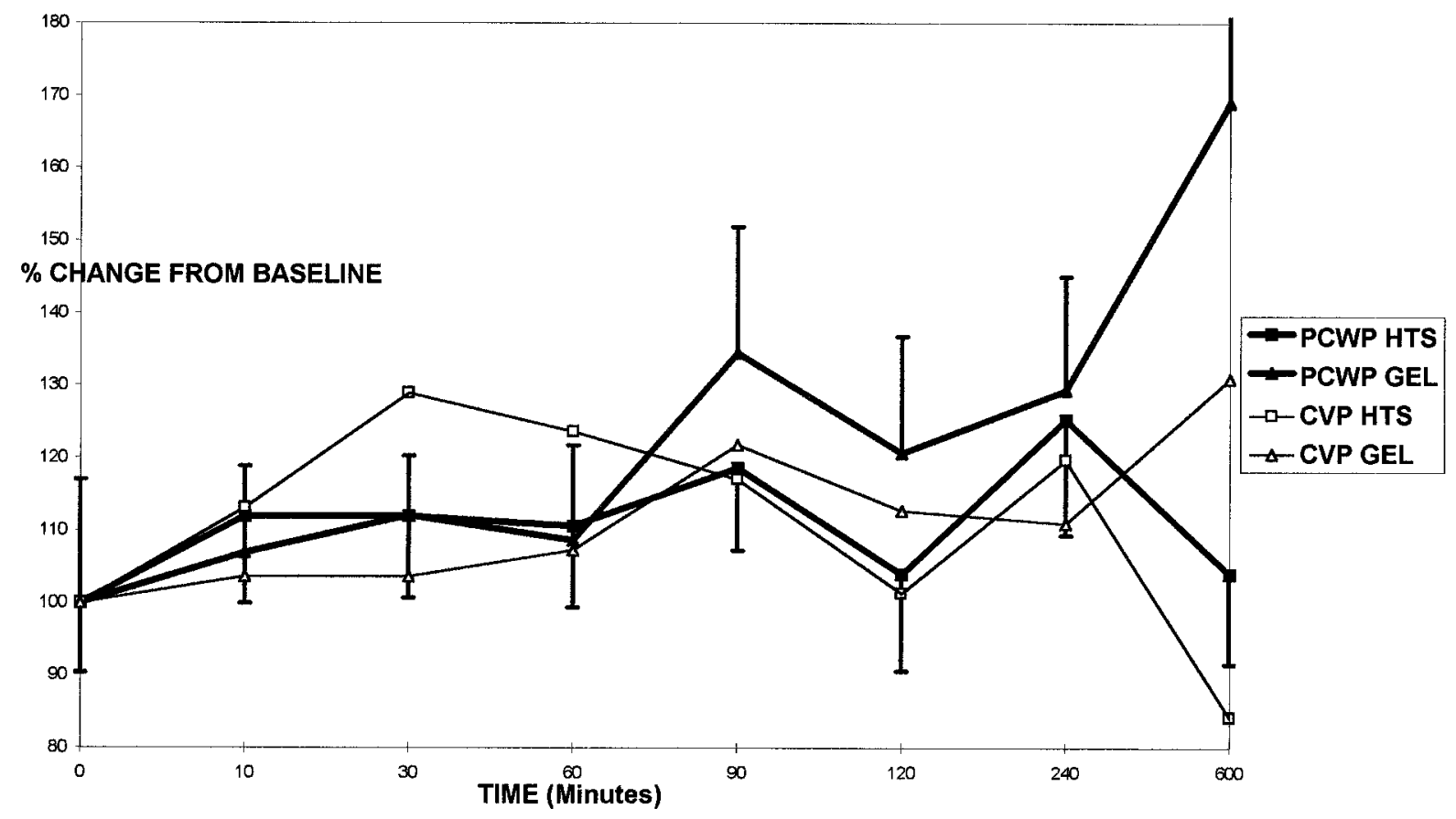

Fig. 5. Interrelationship of the percentage changes in the pulmonary capillary wedge pressure $(P C W P)$ and the central venous pressure $(C V P)$ of the two groups. While the GEL group shows a gradual and parallel rise in the central venous and pulmonary capillary wedge pressures over the observational period, in the HTS group these parameters have a less escalating trend. Values depicted are mean \pm standard error of the mean.

group differences were identified between age, weight, body surface area, preoperative left ventricular ejection fraction, and intraoperative fluid balance (Table I).

In the first 12 postoperative hours, all patients in both groups required additional fluid including blood and GEL. Although the HTS group required less additional fluid in the form of blood and gelatin and the total fluid requirement was less in that group than in the control group, the differences did not reach statistical significance (Table II, Fig. 1).

The net fluid balance in the two groups, however, was significantly different. HTS group had almost double the amount in urinary output by 12 hours $(51.2 \pm 5.8 \mathrm{ml} / \mathrm{kg}$ vs $26.5 \pm 2.9 \mathrm{ml} / \mathrm{kg} ; p=0.0008)$ and achieved a negative balance for that period $(-23$ $\mathrm{ml} \pm 5.6 \mathrm{ml} / \mathrm{kg}$ vs $9 \pm 3.2 \mathrm{ml} / \mathrm{kg} ; p=0.0008)$. Taking the intraoperative balance into account as well, the overall fluid balance at 12 hours was less positive in the HTS group $(29.6 \pm 5.7 \mathrm{ml} / \mathrm{kg}$ vs $63 \pm 7.3 \mathrm{ml} / \mathrm{kg}$; $p=0.007)$.

The urinary output at 24 hours remained high for the HTS group $(66.4 \pm 7 \mathrm{ml} / \mathrm{kg}$ vs $39 \pm 3.3 \mathrm{ml} / \mathrm{kg}$; $p=0.0029)$. This diuresis did not affect either plasma $\mathrm{K}^{+}$level or further $\mathrm{K}^{+}$requirement. In fact, plasma $\mathrm{K}^{+}$levels generally remained higher, but within normal limits, in the HTS group. No tachyarrhythmia occurred in either group. Only a single dose of $20 \mathrm{mg}$ furosemide was given to one of the patients in the GEL group.

Plasma $\mathrm{Na}^{+}$content and osmolarity were significantly higher in the HTS group. Maximum $\mathrm{Na}^{+}$ level in the HTS was $156.9 \mathrm{mEq} / \mathrm{L}$ at 60 minutes. At 12 hours, plasma $\mathrm{Na}^{+}$was significantly higher in the HTS group ( $p=0.0003)$, but by 24 hours there was no difference between the two groups $(p=0.19)$.

Urinary excretion of sodium continued to remain significantly higher in the HTS group until the 24-hour measurements. No significant difference was noted between the plasma creatinine or urea levels of the two groups at either 12 or 24 hours (Table III).

Patients in the HTS group met the extubation criteria at an earlier time period, and this resulted in a significantly shorter $(p=0.029)$ period of ventilatory support. 


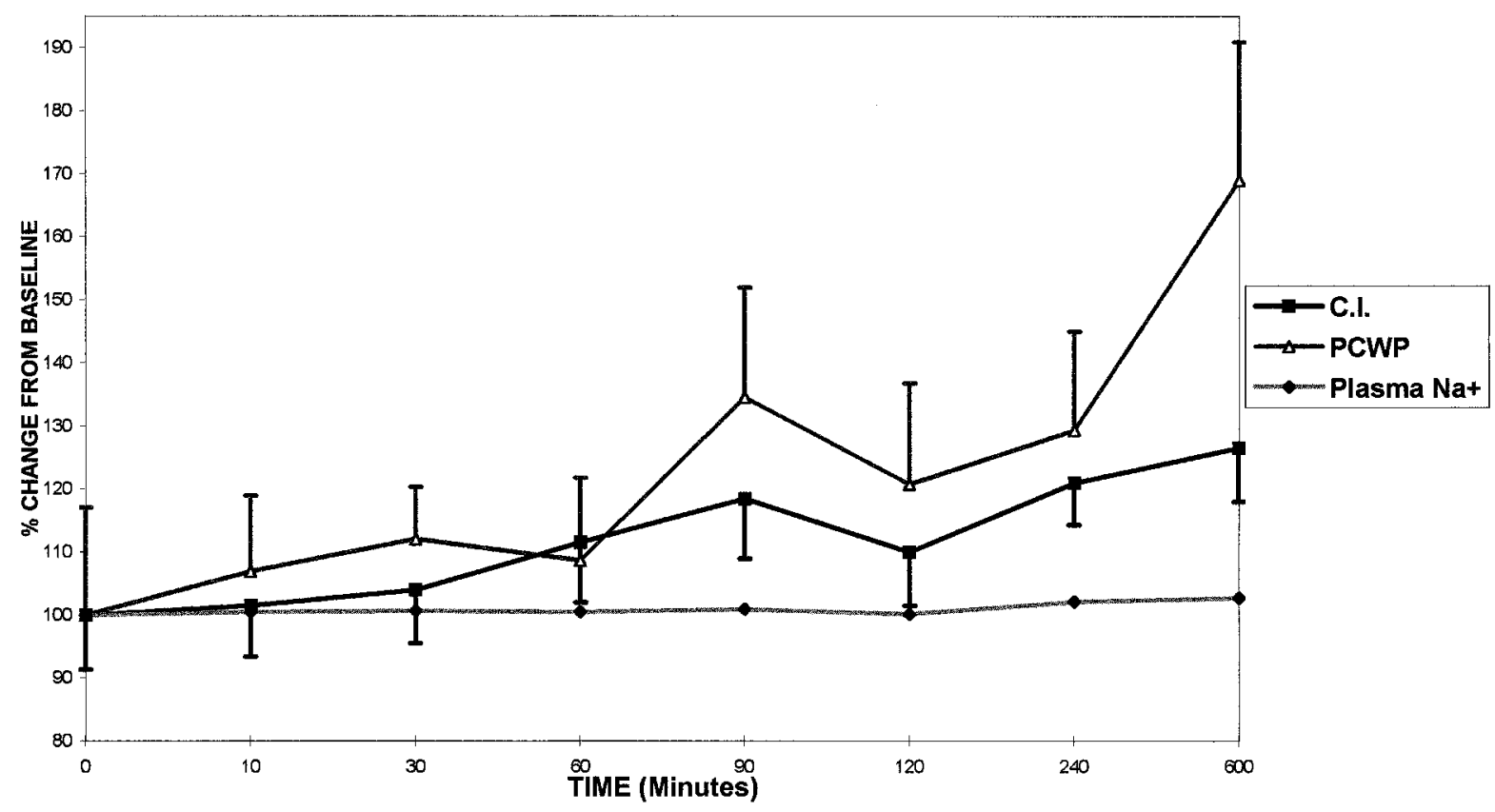

Fig. 6. Interrelationship of the percentage changes in the plasma sodium $\left(\mathrm{Na}^{+}\right)$levels, pulmonary capillary wedge pressure $(P C W P)$ and cardiac index $(C I)$ in the GEL group. A clear preload effect of the infused fluid is evident with parallel increase in the cardiac index along with a concomitant rise in the pulmonary capillary wedge pressure over time, without any appreciable change in the plasma sodium levels. Values depicted are mean \pm the standard error of the mean.

No decrease in the calculated SVRI was noted in the HTS group of patients. It remained within -3 to $+9 \%$ of the baseline mean value for the whole observation period. On the contrary, patients in the GEL group had a gradual fall in SVRI, reaching $72 \%$ of the baseline mean by 10 hours $(p=0.009$, Fig. 2). In contrast, the GEL group had $+9 \%$ to $+20 \%$ higher PVRI at most time points before reaching the baseline mean value at 10 hours. In the HTS group, however, PVRI was significantly lower at 30 minutes $(p=0.019)$, 60 minutes $(p=0.039)$, 120 minutes $(p=0.019)$, and at 4 hours $(p=$ $0.0059)$. Peculiarly, no difference was observed at 90 minutes $(p=0.089)$ (Fig. 3). PVRI in the HTS group had a negative correlation with plasma $\mathrm{Na}^{+}$ and osmolarity at 30 minutes $(p=0.029, r=-0.5)$, 120 minutes $(p=0.039, r=-0.4)$, and at 4 hours $(p=0.0039, r=-0.6)$.

The HTS group showed an early increase in CI, with significant difference from the baseline $(p=$ 0.025 ) at 60 minutes (Fig. 4). Maximum values for pulmonary capillary wedge pressure and central venous pressure in the HTS group were 16 and 20 $\mathrm{mm} \mathrm{Hg}$, respectively. In the GEL group, similar values were 17 and $12 \mathrm{~mm} \mathrm{Hg}$, respectively. The GEL group had a time-related increase in the pulmonary capillary wedge pressure, reaching a maximum of $170 \%$ of baseline at 10 hours, whereas in the HTS group it reached a maximum of $130 \%$ of the baseline at 4 hours (Fig. 5). The GEL group had a linear increase in the CI, along with an increase in the pulmonary capillary wedge pressure, without any correlation to the plasma $\mathrm{Na}^{+}$or its osmolarity (Fig. 6 ). The HTS group, however, had a nonlinear rise in the CI, with a peak of $+31 \%$ occurring at 60 minutes, coinciding with $7.5 \%$ and $8 \%$ increases in the plasma $\mathrm{Na}^{+}$and osmolarity, respectively (Fig. 7). A positive correlation between plasma $\mathrm{Na}^{+}$and CI was noted at 30 minutes ( $p=0.009, r=0.53$ ), 60 minutes $(p=0.019, r=0.51)$, and 120 minutes $(p=$ $0.019, r=0.5)$. Again, the correlation was blunted at 90 minutes. After the 60-minute peak, the CI in the HTS group maintained a plateau of between +20 to $+30 \%$ above the baseline, closely following the GEL group.

No untoward metabolic, renal, neurologic, cardiovascular, or hematologic effects were seen in any of the HTS group patients. One patient (GEL group) 


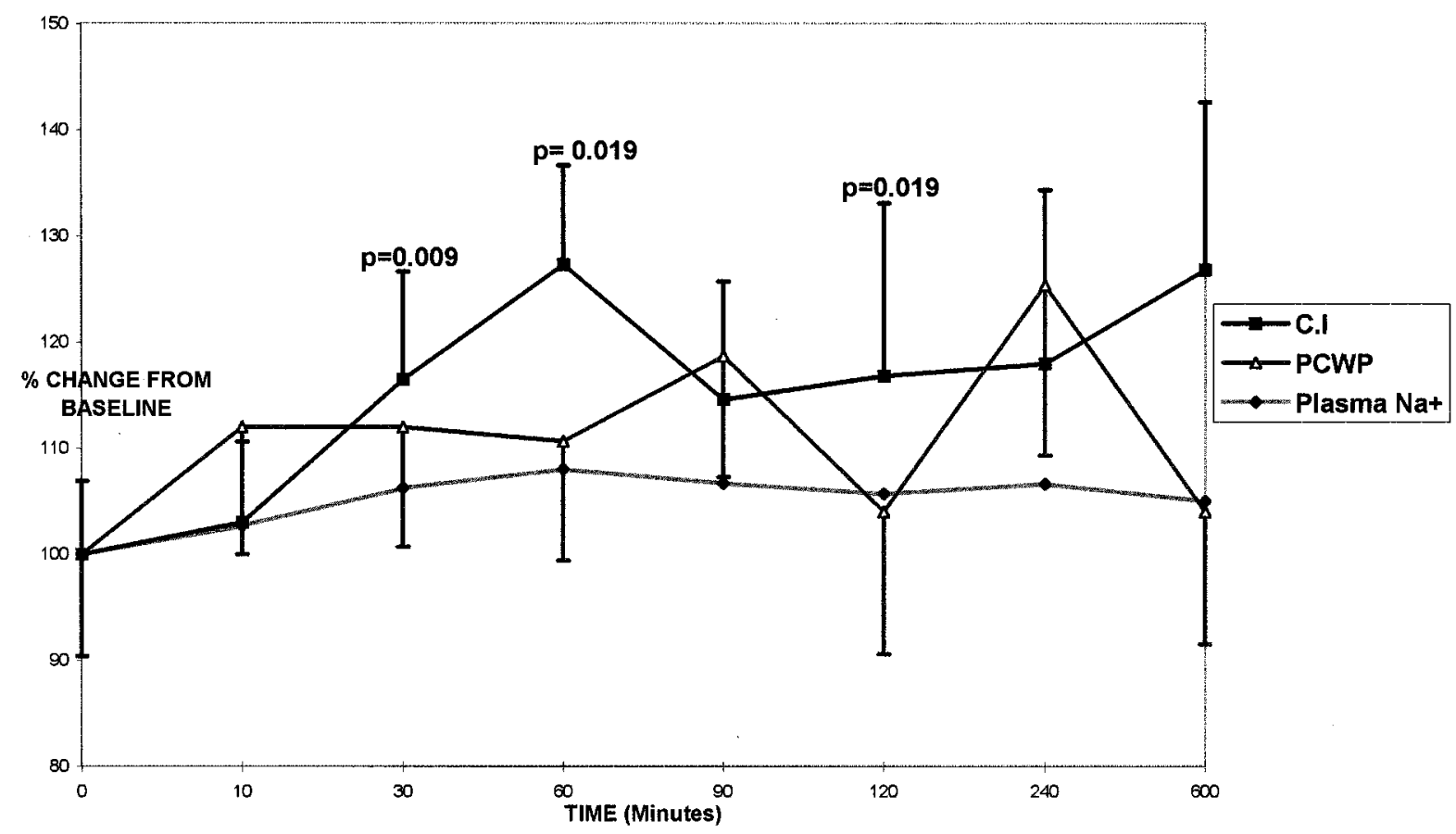

Fig. 7. Interrelationship of the percentage changes in the plasma sodium $\left(\mathrm{Na}^{+}\right)$levels, pulmonary capillary wedge pressure $(P C W P)$ and cardiac index $(C I)$ in the HTS group. Note the early rapid increase in the cardiac index along with concomitant rise in the plasma sodium levels in the presence of relatively stable and lower pulmonary capillary wedge pressures, possibly exhibiting an inotropic effect of HTSinduced hypernatremia. Values depicted are mean \pm standard error of the mean.

with a severely calcific aorta had a cerebrovascular accident 36 hours after discharge from the intensive treatment unit. In another patient from the HTS group a septic syndrome developed in the intensive treatment unit. Both had a slow but successful recovery.

\section{Discussion}

The results of this study are in contrast to the conventional wisdom of the therapy of the failing heart. It may be that the nostrum of avoiding administration of extra sodium in this circumstance is incorrect. In the present study, although the two groups had similar fluid retention during the operation, 12 hours after the operation the mean net fluid balance in the HTS group was less by 33.5 $\mathrm{ml} / \mathrm{kg}(+29.57 \mathrm{ml} / \mathrm{kg}$ vs $+63.08 \mathrm{ml} / \mathrm{kg}$ for GEL, $p=$ $0.007)$. This difference was mainly due to the extra diuresis in the HTS patients $(p=0.00089)$, rather than significantly different amounts of postoperative fluid infusion $(p=0.29)$. This "diuresis without additional fluid requirement" was associated with improved hemodynamics and respiratory function.
Does this represent a correction of the intracellular fluid retention that may occur during $\mathrm{CPB}$ ?

Fluid retention with CPB is estimated to be 800 $\mathrm{ml} / \mathrm{m}^{2}$ per hour of CPB time. ${ }^{12}$ Customarily, this extra fluid is regarded to be sequestered mainly in the interstitial part of the extracellular fluid compartment. ${ }^{13}$ Variations in the intracellular water after CPB and its implication on cardiorespiratory function are not known. Direct measurement of intracellular water is difficult; measurements are derived by subtracting extracellular fluid volume from total body water. However the isotopes most commonly used for estimation of extracellular fluid volume, Br82 and S35, do penetrate the cells. Breckenridge, Digerness, and Kirklin, ${ }^{13}$ using inulin, which does not cross into the cells, have found a smaller increase in the $\mathrm{Br} 82$ space as compared with inulin space $(+18.6 \%$ vs $+33 \%)$. This observation highlights the uncertainty regarding measurement of the exact amount of the fluid retained in different body compartments after CPB.

On the other hand, there is evidence to suggest that CPB may increase intracellular water content. 
Generalized capillary endothelial swelling has been documented after $\mathrm{CPB}^{14}$ Similarly, intracellular fluid retention is noted to occur during protracted low perfusion, situations that essentially mimic a CPB state (for example, hemorrhagic shock ${ }^{15}$ ) and after major operations. ${ }^{16}$

If a significant increase in intracellular water content with visceral and endothelial edema contributes to postoperative multiorgan dysfunction, then the choice of volume replacement fluid may be very important. A medium would be desirable that can translocate volume from intracellular fluid and the extracellular fluid and encourage its excretion. In this regard, HTS and colloids differ in their target area for mobilization of fluid.

Colloids move water from the interstitium into the intravascular compartment, whereas HTS shifts water out of the intracellular compartment. ${ }^{17}$ The reason is that the cell membrane restricts free movement of electrolytes whereas the capillary endothelium is freely permeable to $\mathrm{Na}^{+}$and $\mathrm{Cl}^{-}{ }^{-18}$ Along with this fluid shift, direct renal vasodilatation and increased glomerular filtration rate seen with HTS $^{19}$ should make it more useful in the post-CPB period.

HTS has a threefold to sevenfold plasma volume expansion effect as compared with a 1:1 effect of the synthetic colloids. Besides, the speed with which HTS expands plasma volume is almost five and ten times faster than that of synthetic colloids and isotonic saline solution, respectively. ${ }^{18,20}$

HTS infusion produces a sudden increase in the plasma osmolarity, which leads to quick efflux of fluid, first out of the cells that are contiguous with the plasma (that is, red blood cells and the capillary endothelium) and then from the interstitium. Capillary endothelium is freely permeable to $\mathrm{Na}^{+}$and $\mathrm{Cl}^{-}$, and within 30 minutes the interstitial space establishes sodium equilibration with the plasma. ${ }^{18}$ Unlike capillary endothelium, the tissue cells restrict free movement of electrolytes and hence steadily give up water as the interstitial sodium concentration rises. By the time extracellular fluid comes into new salt equilibrium, it is estimated that the intracellular fluid has a net volume deficit of approximately $3 \%$ to $6 \%$, which is gained by plasma and the interstitial space in almost equal ratios. ${ }^{18,21}$ Such osmotic translocation of intracellular water is noted to improve cardiac compliance. ${ }^{18}$ Besides, there are reports that HTS has a direct inotropic effect on myocardium ${ }^{22}$ and improves microcirculatory flow as a result of hemodilution, decreased capillary hydraulic resistance, and improved red blood cell rheology. ${ }^{23}$

In summary, the patients receiving HTS were extubated significantly earlier than those receiving conventional fluid replacement with a synthetic colloid. A decrease in the need for inotropic drugs and a decrease in PVRI were also noted. These data may support the hypothesis that generalized intracellular edema contributes to post-CPB multiorgan dysfunction and that there is therefore a role for HTS in counteracting this complication.

A larger sample, with measurement of intracellular water content, would be required to validate this hypothesis. From these preliminary data, however, it would be tempting to observe the cardiopulmonary effects of hypernatremic hyperosmolarity if it is maintained at or above $8 \%$ by continuous infusion of HTS.

We believe that HTS has a beneficial role to play in CPB-based procedures. Its use as an addition to pump prime, postoperative fluid replacement, and in situations of multiorgan dysfunction after CPB need further evaluation.

\section{REFERENCES}

1. Gonzalez J, Morrisey T, Byrne T, Rizzo R, Wilmore D. Bioelectric impedance detects fluid retention in patients undergoing cardiopulmonary bypass. J Thorac Cardiovasc Surg 1995;110:111-8.

2. Tao W, Zwischenberger JB, Nguyen TT, et al. Gut mucosal ischemia during cardiopulmonary bypass results from blood flow redistribution and increased oxygen demand. J Thorac Cardiovasc Surg 1995;110:819-28.

3. Penfield WG. The treatment of severe and progressive hemorrhage by intravenous injections. Am J Physiol 1919;48: 121-8.

4. Moylan JA, Reckler JM, Mason AD. Resuscitation with hypertonic lactate saline in thermal injury. Am J Surg 1973; 125:580-4.

5. DeFilippe J, Timoner J, Velasco IT, et al. Treatment of refractory hypovolaemic shock by $7.5 \%$ sodium chloride injections. Lancet 1980;2:1002-4.

6. Vassar MJ, Fischer RP, O'Brien PE, et al. A multicenter trial for resuscitation of injured patients with $7.5 \%$ sodium chloride: the effect of added Dextran 70 . The multicenter group for the study of hypertonic saline in trauma patients. Arch Surg 1993;128:1003-11.

7. Auler JOC, Pereira C, Gomide-Amaral V, et al. Hemodynamic effects of hypertonic sodium chloride during surgical treatment of aortic aneurysms. Surgery 1987;101:594-601.

8. Ramires JA, Serrano JCV, Cesar LA, et al. Acute hemodynamic effects of hypertonic (7.5\%) saline infusion in patients with cardiogenic shock due to right ventricular infarction. Circ Shock 1992;37:220-5.

9. Boldt J, Kling D, Weidler B, et al. Acute preoperative haemodilution in cardiac surgery: volume replacement with a hypertonic saline-hydroxyethyl starch solution. J Cardiothorac Vasc Anaesth 1991;5:23-8. 
10. Cross JS, Gruber DP, Gann DS, et al. Hypertonic saline attenuates the hormonal response to injury. Ann Surg 1989; 209:684-92.

11. Halvorsen L, Gunther RA, Dubick MA, et al. Dose response characteristics of hypertonic saline dextran solutions. J Trauma 1991;31:785-94.

12. Utley JR, Stephens DB. Fluid balance during cardiopulmonary bypass. In: Utley JR, editor. Pathophysiology and technique of cardiopulmonary bypass, Vol 1. Baltimore: Williams \& Wilkins; 1982. p. 23.

13. Breckenridge IM, Digerness SB, Kirklin JW. Increased extracellular fluid after open intracardiac operation. Surg Gynecol Obstet 1970;131:53-8.

14. Al-Khaja N, Belboul A, Bergman P, et al. Cutaneous microcirculation and blood rheology following cardiopulmonary bypass: laser Doppler flowmetric and blood cell rheologic studies. Scand J Thorac Cardiovasc Surg 1988; 22:149-53.

15. Nakayama S, Kramer GC, Carlsen RC, et al. Infusion of very hypertonic saline to bled rats: membrane potentials and fluid shifts. J Surg Res 1985;38:180-6.

16. Flear CTG, Pickering J, McNeill IF. Observations on water and electrolyte changes in skeletal muscle during major surgery. J Surg Res 1969;9:369.

17. Croft D, Dion YM, Dumont M, et al. Cardiac compliance and effects of hypertonic saline. Can J Surg 1992;35:139-44.

18. Mazzoni MC, Borgstrom P, Arfors KE, et al. Dynamic fluid redistribution in hyperosmotic resuscitation of hypovolemic hemorrhage. Am J Physiol 1988;255:H629-37.

19. Fujita T, Matsuda Y, Shibamoto T, et al. Effect of hypertonic saline infusion on renal vascular resistance in anesthetized dogs. Jpn J Physiol 1991;41:653-63.

20. Geortz AW, Tobias M, Lindner KH, et al. Effect of $7.2 \%$ hypertonic saline $/ 6 \%$ hetastarch on left ventricular contractility in anesthetized humans. Anesthesiology 1995;82:1389-95.

21. Kramer GC, Perron PR, Lindsey DC, et al. Small-volume resuscitation with hypertonic saline dextran solution. Surgery 1986;100:239-47.

22. Ogata H, Luo XX. Effects of hypertonic saline solution $(20 \%)$ on cardiodynamics during hemorrhagic shock. Circ Shock 1993;41:113-8.

23. Mazzoni MC, Borgstrom P, Intaglietta $M$, et al. Capillary narrowing in hemorrhagic shock is rectified by hyperosmotic saline-dextran reinfusion. Circ Shock 1990;31:407-18.

Fluid Balance $(\mathrm{ml} / \mathrm{Kg})$ at 12 hours \& Extubation time (Hours) (MEDIAN VALUES)

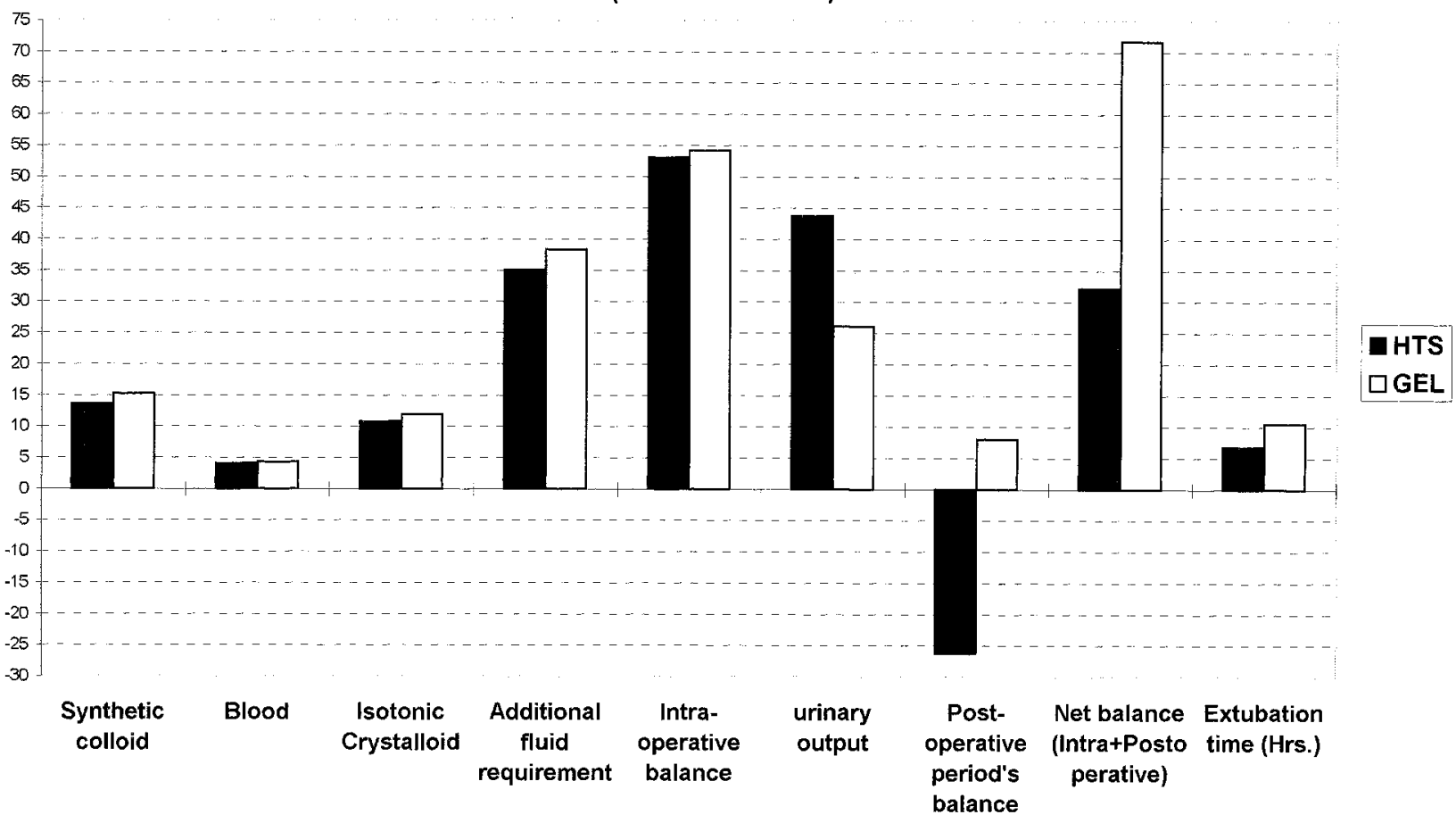

Appendix Fig. 1. Fluid balance and extubation time (median values). 


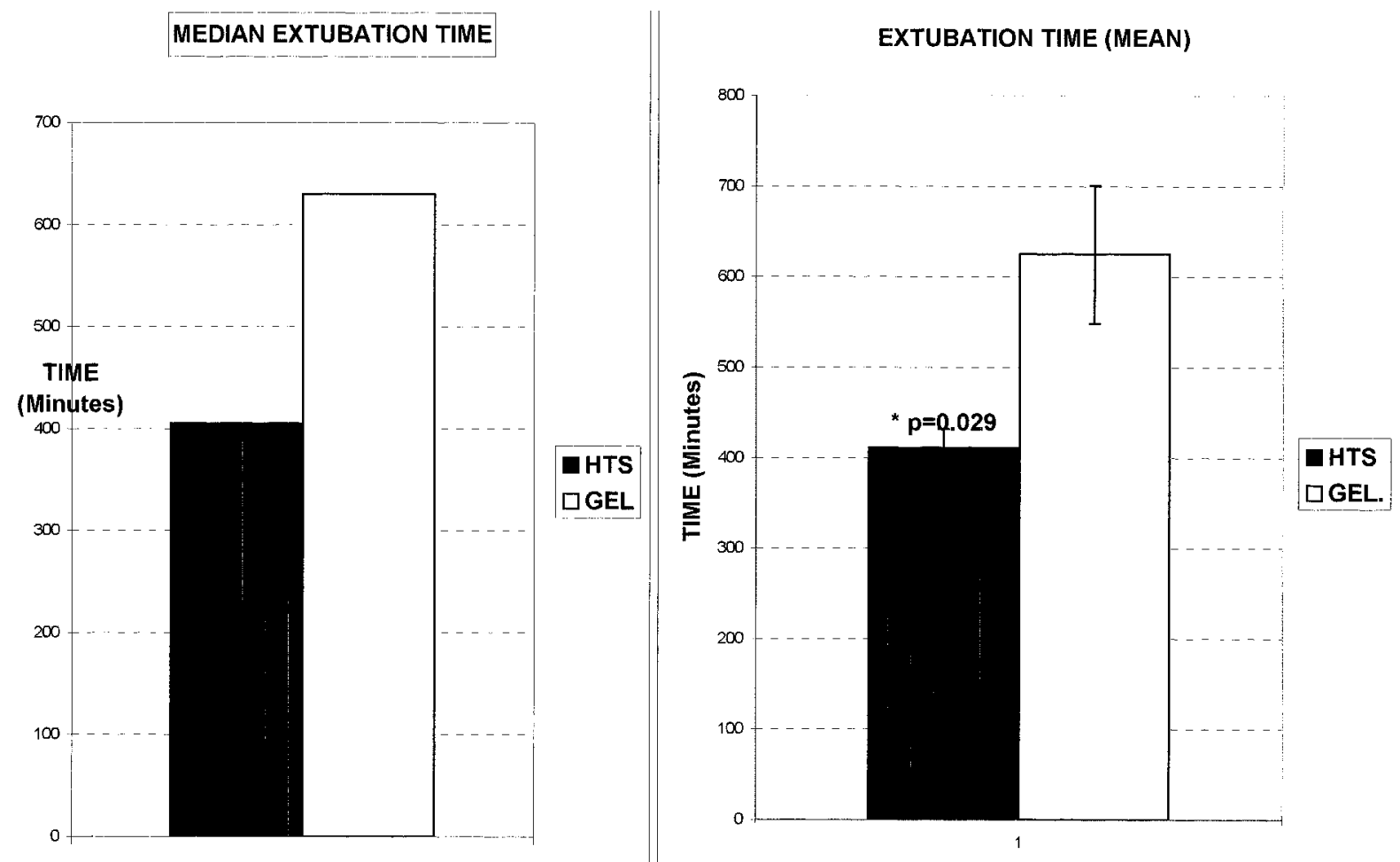

Appendix Fig. 2. Median (left) and mean (right) extubation times.

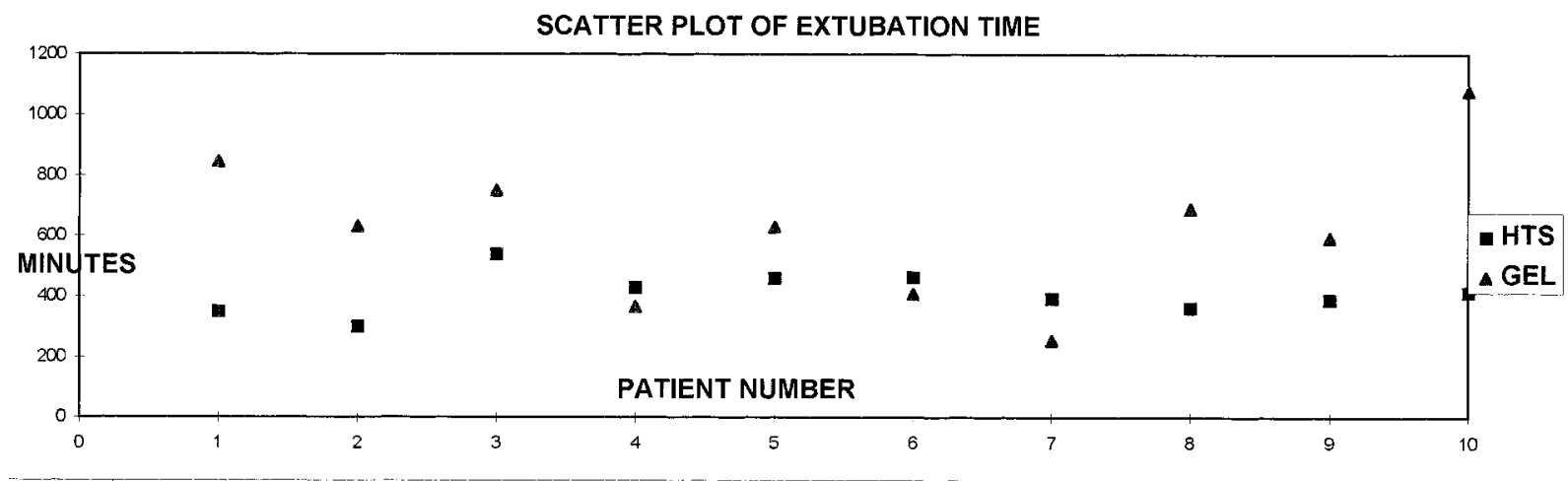

SCATTER PLOT FOR 12 HOUR'S URINARY OUTPUT.

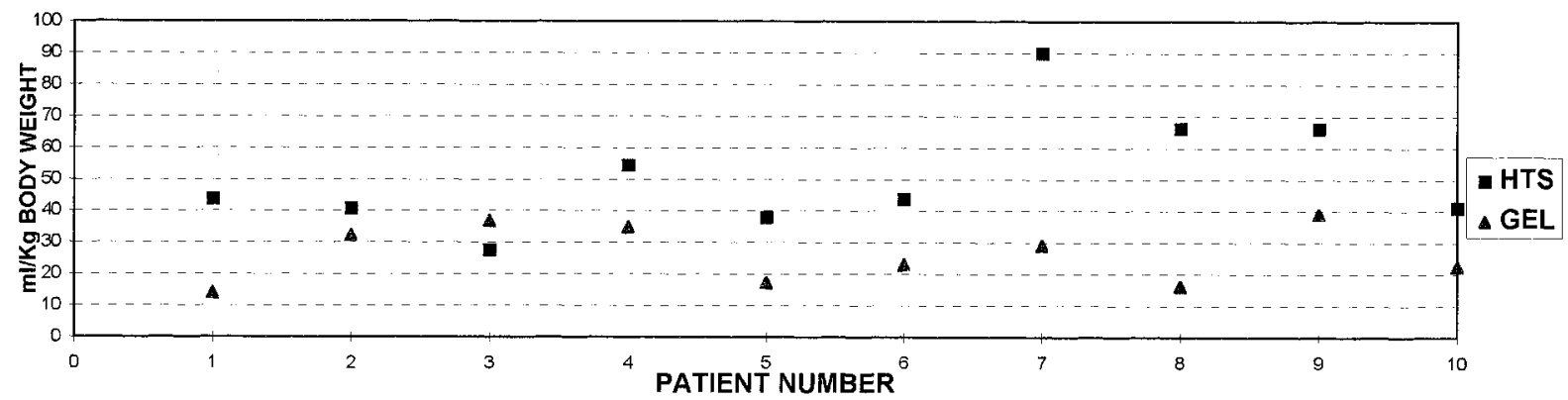

Appendix Fig. 3. Scatter plots of extubation time (top) and urinary output (bottom). 


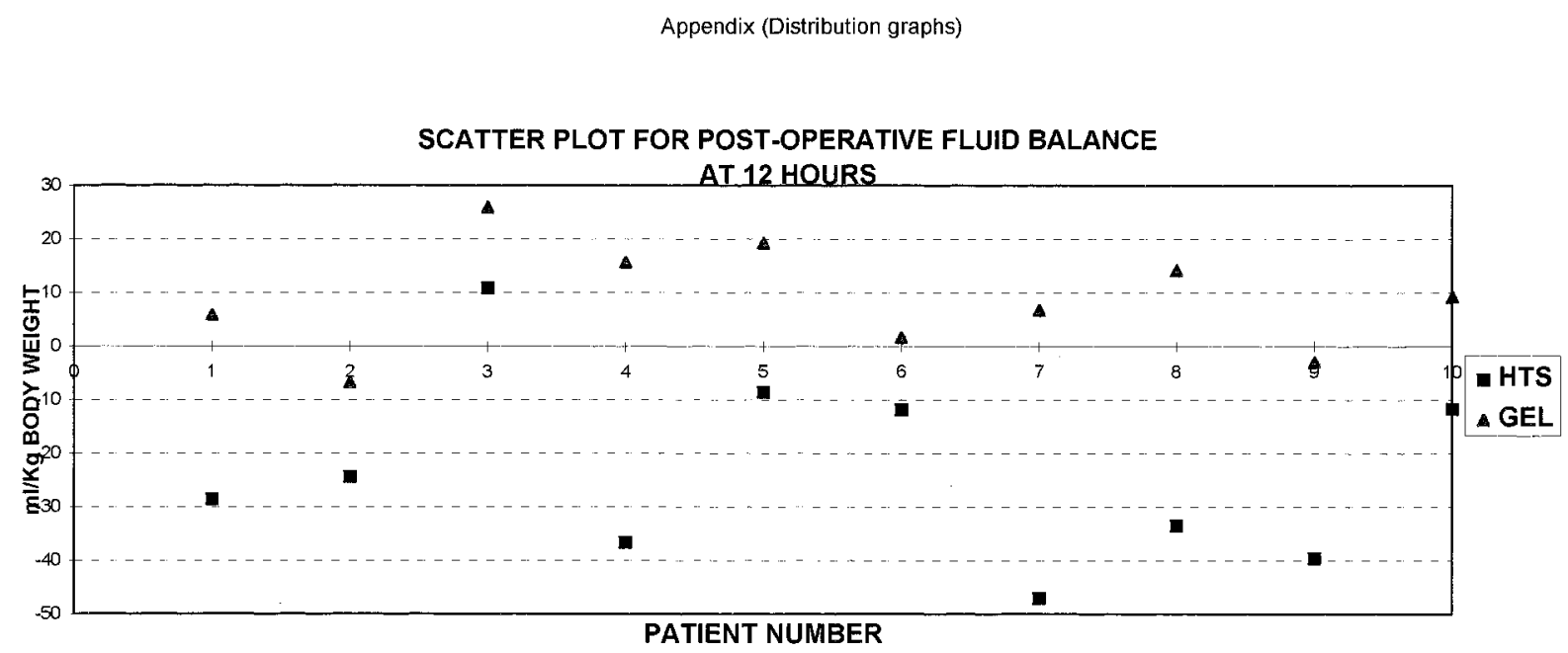

Appendix Fig. 4. Scatter plot for postoperative fluid balance. 